\title{
Development of Gate Game Applications Using the IMSDD Method
}

\section{Pembangunan Aplikasi Game Gerbang Dengan Menggunakan Metode IMSDD}

\author{
Nyimas Humairoh Khairunnissa ${ }^{1}$, Muhamad Akbar ${ }^{2 *}$, Siti Sauda ${ }^{3}$. \\ Teknik Informatika, Universitas Bina Darma, Palembang, Indonesia \\ Email: aoithecielo@gmail.com ${ }^{1}$,muhamad.akbar@binadarma.ac.id ${ }^{2}$, \\ siti_sauda@binadarma.ac.id ${ }^{3}$ \\ *Corresponding Author : muhamad.akbar@binadarma.ac.id
}

\begin{abstract}
Abstrak
According to the KBBI (Indonesian Dictionary) History is an event that has happened in the past and actually bappened. But history is difficult to learn and is bored because it must be memorized. Therefore the writer tries to make a game application about the history of Indonesia called Gerbang ("Gerakan Bangsa"). This game has a theme about the history of colonialism in Indonesia. By using the IMSDD (Interactive Multimedia System of Design and Development) method and the Unity application, the Gerbang game was created. This game runs on the Android operating system to be easy to use and attract the user's interest. In the IMSDD development method, there are 4 stages, namely: 1. System Requirements, 2. Design Consideration, 3. Implementation, 4. Evaluation. Where each stage ultimately forms the Gate game which has 6 different question themes consisting of Japanese, English, French, Dutch, Spanish, and Portuguese. These names are the names of countries that had colonized Indonesia. With these 6 different themes, users can know the extent of their knowledge about the colonialists when they occupied Indonesia in the past.
\end{abstract}

Kata Kunci: IMSDD, Sejarah, game Gerbang

\section{PENDAHULUAN}

Sejarah merupakan bagian terpenting dari sebuah pendidik. Mengingat bahwa Sejarah merupakan salah satu faktor yang mampu membentuk karakter dan moral bangsa, pentingnya pelajaran Sejarah sejak usia dini membuat, sejarah telah masuk ke dalam salah satu kurikulum pembelajaran wajib sejak masa bangku Sekolah Dasar. Namun, sayangnya, seiring dengan berlalunya waktu, ilmu sejarah yang dipelajari akan semakin memudar. Padahal, dengan lebih mengetahui sejarah Indonesia, hal itu juga akan menanamkan rasa cinta akan tanah air dan nasionalisme di dalam diri.

Seperti yang diunggah dalam halaman tirto.id, sebuah artikel yang ditulis oleh Petrik Matanasari membahas tentang pelajaran sejarah yang cenderung tidak disukai kalangan pelajar. Di dalam artikel tersebut menyebutkan bahwa sejarah adalah pelajaran menghafal. Bahkan bocah yang semula suka pada sejarah karena pengalaman berjalan-jalan mengunjungi Museum atau menonton film sejarah, bisa hilang rasa sukanya pada sejarah karena begitu di sekolah dijejali banyak hafalan. Hal ini, tentu tidak boleh dibiarkan begitu

This work is licensed under a Creative Commons Attribution 4.0 International License. 
saja. Terutama sejarah prihal masa penjajahan Indonesia, dimana para pejuang dan pahlawan memerangi para penjajah, tidak boleh dilupakan. Karena itu, di dalam penelitian ini, agar pembelajaran kembali terasa lebih menyenangkan, dibuatlah sebuah game berbasis android yang bernama Gerbang atau singkatan dari Gerakan Bangsa.

Game ini dibuat dengan menggunakan Metode pengembangan IMSDD (Interactive Multimedia System of Design and Development) yang dikembangkan oleh Mohammad Dastbaz, game Gerbang akan dibuat melalui empat tahapan, yaitu: System Requirement, Design Consideration, Implementation, dan Evaluation (Dastbaz, 2003). Pada tahap pembangunan game, game akan dibuat dengan menggunakan software pembuat game, Unity 3D. Software yang dibangun pada tahun 2004 oleh David Helgason, Nicholas Francis dan Joachim Ante ini, merupakan software yang sudah terkenal di kalangan para pembuat game. Aplikasi yang cenderung mudah untuk digunakan, sangat membantu para pengembang untuk menciptakan kreatifitas mereka didalam bidang Teknologi.

\section{METODOLOGI PENELITIAN}

Dalam pembangunan game Gerbang berbasis Android, penulis menggunakan metode Penelitian Tindakan atau Action Research. Action research dalam pandangan tradisional adalah suatu kerangka penelitian pemecahan masalah, dimana terjadi kolaborasi antara peneliti dengan client dalam mencapai tujuan (Sulaksana, 2004)

Tujuan yang dicapai dari metode ini akan berakhir tidak hanya pada situasi tertentu, melainkan terus dikembangkan berupa aplikasi atau teori, kemudian hasilnya akan dipublikasikan ke masyarakat dengan tujuan riset (Madya, 2006).

\subsection{Metode Pengumpulan Data}

Di dalam penelitian ini, tentulah memerlukan beberapa data. Untuk dapat mengumpulkan beberapa informasi yang diperlukan dalam pembangunan game Gerbang, menggunakan dua sumber, yaitu sumber Primer dan sumber Sekunder. Menurut Sugiyono (2015), ke dua sumber itu memiliki pengertian yang berbeda.

Sumber Primer adalah sumber data yang langsung memberikan data kepada pengumpul data. Sumber Sekunder merupakan sumber yang tidak langsung memberikan data kepada pengumpul data.

\subsection{Metode Pengembangan}

Di dalam pembuatan game ini, menggunakan metode Interactive Multimedia System of Design and Development (IMSDD) yang dikembangkan oleh Mohammad Dastbaz. Menurut Dastbaz (2003) di dalam bukunya yang berjudul Interactive Multimedia System, Metode Interactive Multimedia System of Design and Development (IMSDD) adalah suatu metode perancangan dan pengembangan sistem aplikasi multimedia interaktif yang terdiri atas tahapan-tahapan yang terstruktur. IMSDD Dibagi menjadi empat tahapan, yaitu:

\section{a. System Requirement}

Pada tahapan System Requirement, sangat mirip dengan metode waterfall. Tahapan ini di dalam game Gerbang, akan membahas prihal tujuan pembuatan game yang berupa outline, pertimbangan platform apa yang akan digunakan bersamaan dengan tools apa saja yang diperlukan di dalam pembuatan game Gerbang berbasis Android ini. 
Vol. 2, No. 1, March 2020

p-ISSN: 2656-5935 http://journal-isi.org/index.php/isi

e-ISSN: 2656-4882

\section{b. Design Consideretion}

Pada tahap ke dua, Design Consideretion, game Gerbang akan mulai diperkirakan wujudnya. Membuat logika dan alur game lalu membuat prototype game dengan beberapa penjelasan penggunaan tipe dan fitur kontrolnya.

\section{c. Implementation}

Ketika tahapan Design Consideretion telah selesai, tahapan Implementation adalah yang selanjutnya. Tahapan ini adalah pengcodingan. Dimana game sudah mulai dicoding dan diujicoba.

\section{d. Evaluation.}

Evaluation merupakan tahapan akhir dimana game Gerbang yang telah selesai, akan diujicoba oleh beberapa pemakai. Pada bagian ini, game Gerbang akan dievaluasi apakah telah sesuai dengan tujuan awal pembuatannya atau tidak. Namun, karena batasan masalah yang dimiliki penulis, game Gerbang tidak akan melakukan tahap terakhir ini.

\section{HASIL}

\subsection{System Requirement}

Ini merupakan tahapan awal sebelum game Gerbang di buat. Pada tahapan System Requirement, game gerbang akan menjabarkan beberapa aspek persiapan sebelum game benarbenar dibuat. Diantaranya adalah:

\subsubsection{System Definition}

Aplikasi game Gerbang merupakan game edukasi berbasis Android. Kata Gerbang sendiri merupakan singkatan dari Gerakan Bangsa. Game yang dibangun merupakan game quiz dimana user / pemain menjawab setiap pertanyaan yang diajukan. Setiap pertanyaan yang diberikan, merupakan pertanyaan prihal setiap negara yang pernah menjajah Indonesia.

Masing-masing tema pada pertanyaan terbagi menjadi enam negara, yaitu: Jepang, Inggris, Prancis, Belanda, Spanyol dan Portugis. Nama-nama negara terebut merupakan negara yang pernah menjajah Indonesia sebelum Indonesia merdeka. Pada setiap negara, memiliki 50 soal yang akan ditampilkan secara acak kepada user/pemain. Tidak ada level pada permainan, tetapi $u s e r /$ pemain bisa memilih untuk negara mana yang ingin mereka jawab di dalam game tanya-jawab ini.

Karena semua pertanyaan yang dibuat merupakan informasi yang didapatkan dari beberapa sumber buku sejarah, memainkan permainan ini juga merupakan jenis belajar sambil bermain. Diharapkan ketika menjawab setiap soal yang diberikan, pemain dapat memanfaatkannya sebagai alternatif lain dari belajar dan merangsang pemain untuk lebih mencintai negara sendiri setelah menyadari arti penting dari perjuangan panjang negara Indonesia untuk mencapai kata 'kemerdekaan'.

\subsubsection{User's Profile and Needs}

Dari isi soal yang dipilih di dalam Game Gerbang, user / pengguna merupakan kalangan Siswa Menengah Pertama (SMP) dan ke atas. Tujuan dari pembuatan game ini sendiri untuk mengulang kembali ingatan tentang sejarah Indonesia dan menambah wawasan guna menanam rasa nasionalisme pemain dengan pengetahuan tentang Sejarah 
Penjajahan di Indonesia. Diharapkan juga dengan memainkan game ini, para pelajar juga dapat menikmati Pelajaran Sejarah yang biasanya terasa membosankan karena terlalu banyak menghafal

\subsubsection{Hardware and Software Concideration}

Pertimbanga dalam pembuatan, memerlukan beberapa perangkat keras dan juga perangkat lunak. Berikut di bawah ini merupakan hal-hal yang diperlukan untuk pembuatan aplikasi Game Gerbang:

a. Hardware:
1. Laptop ASUS
2. WACOM
3. Samsung $\mathrm{J} 2$
4. Kabel USB
5. Mouse
1. Unity 3D
2. Medi Bang Paint Pro
3. Microsoft Word
4. Visual Studio 2017
5. Android Studio
6. AudaCity
7. OpenShot Video Editor
8. Fire Alpaca

b. Software:

\subsubsection{Delivery Concideration}

Untuk tahap ini, game Gerbang hanya disebarkan melalui media sosial dan beberapa orang teman. Game yang dibangun bersifat Offline, sehingga tidak akan ada update.

\subsection{Design Concideration}

Berikut ini merupakan tahapan awal rancangan game gerbang. Persiapan dan bahanbahan yang akan diperlukan untuk interface dan lain sebagainya. Semuanya disusun menurut di bawah ini:

\subsubsection{Design Metaphor}

Design Metaphor adalah bagian dari perancangan yang bertujuan untuk mengadopsi fakta dari dunia nyata ke dalam sebuah aplikasi yang siap pakai. Pada game Gerbang, fakta yang diambil merupakan referensi dari beberapa buku Sejarah yang diubah menjadi soalsoal yang akan user jawab di dalam permainan. Soal-soal sejarah ini diambil dari e-book Sejarah untuk siswa SMP dan juga SMA, tetapi beberapa juga merupakan e-book yang ditulis oleh M Adnan Amal tentang Kepulauan Rempah-Rempah dan beberapa buku lainnya.

\subsubsection{Information Type and Format}

Format dan tipe informasi yang akan diintegrasikan ke dalam game Gerbang terdiri dari:

1. Gambar (PNG)

2. Suara (MP3)

3. Video (MP4)

4. Animasi (Meta) 
Vol. 2, No. 1, March 2020

\subsubsection{Navigation Structure}

Struktur navigasi game Gerbang dimulai dari user menginstal aplikasi Game Gerbang dan akan langsung disuguhkan ke dalam Menu Utama yang terdapat tiga buttom yaitu Permainan, Tutorial dan Keluar.

Sesuai dengan nama yang tertera di ketiga button Menu Utama, apabila User ingin terlebih dahulu melihat cara bermain, pemain bisa menekan buttom Tutorial dan melihat cara bermain game Gerbang, tetapi bila user ingin langsung memainkan permainan, user tinggal menekan buttom Permainan.

Sebelum bermain, pemain akan menemukan pilihan karakter yang akan digunakan, setelah memilih, pemain akan dibawa ke bagian pilih level. Masing-masing level tidak akan langsung terbuka kecuali pemain telah menyelesaikan level yang sebelumnya. Sehingga, apabila user baru pertama memainkannya, yang terbuka hanyalah level pertama.

Lalu, apabila user ingin keluar dari permainan, bisa langung menekan buttom keluar dan pemain akan secara otomatis keluar dari aplikasi permainan game Gerbang.

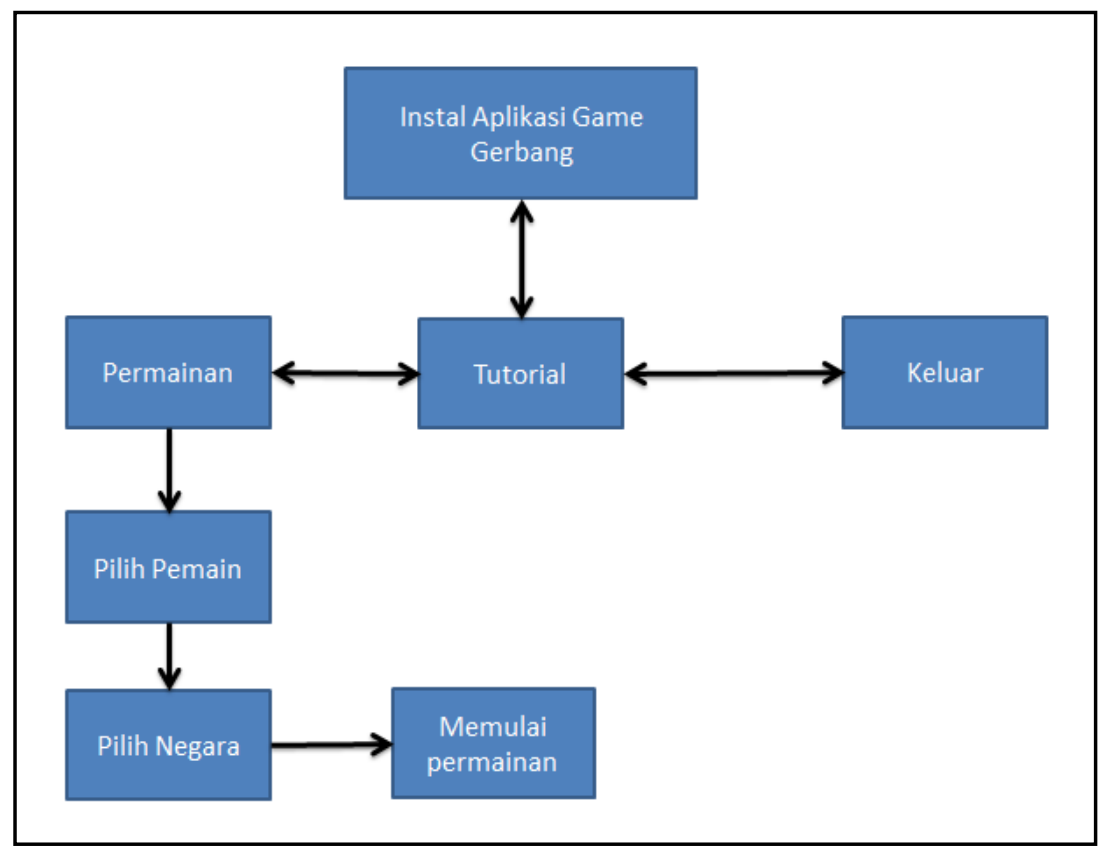

Gambar 3.1 Navigation Structure game Gerbang

\subsubsection{Media Preparation and Integration Issue}

Bagian ini merupakan tahapan perancangan dengan memperhatikan media yang akan diintegrasikan ke dalam pembuatan game Gerbang, dimana setiap media akan satu persatu membentuk sistem yang utuh. Media yang dimaksudkan seperti gambar, suara dan video yang akan disatukan dengan baik hingga memberikan efek visual dan suara yang menyenangkan. 
Vol. 2, No. 1, March 2020

p-ISSN: 2656-5935 http://journal-isi.org/index.php/isi

e-ISSN: 2656-4882

a. Media Preparation

Pada tahap mempersiapkan media-media yang akan digunakan, sebagian mendownload dari asset yang tersedia secara geratis di situs resmi Unity atau beberapa situs website game yang memang menyediakannya. Beberapa hal seperti karakter yang akan digunakan user, digambar sendiri oleh penulis.

b. Integration Issue

Bagian ini merupakan bagian dimana setiap media yang telah dikumpulkan, akan diseleksi dan digunakan satu persatu untuk mulai disusun menjadi interface yang sesuai dengan sistem yang diperlukan.

\subsection{Implementation}

Di dalam IMSDD, Implementation terdiri dari 2 tahapan, yaitu Prototype dan Beta Testing. Prototype merupakan aplikasi yang telah jadi dan telah bisa melakukan tatap muka sementara Beta Testing adalah proses dimana aplikasi akan di tes apakah setiap buttom dan sistem dapat bekerja sesuai dengan yang diharapkan atau tidak.

\subsubsection{Prototype}

a. Bagian Menu

Untuk mempermudah pemain apakah ingin memulai permainan ataukah melihat tutorial, pada bagian menu terdapat 3 button utama. Permainan, Tutorial dan Keluar. Pada bagian Menu, kedua karakter pemain ditampilkan, untuk memperkuat suasana putra dan putri bangsa.

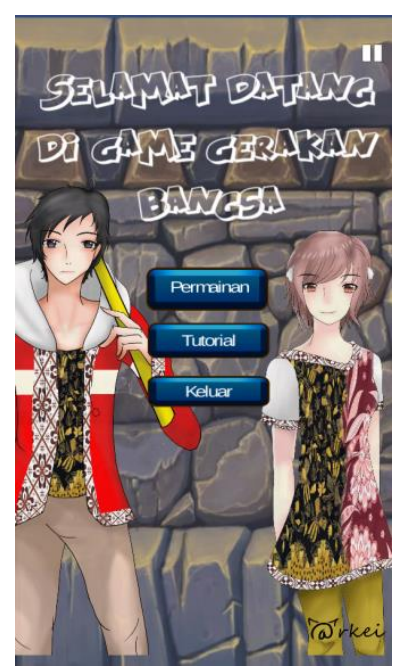

Gambar 3.2: Menut Utama

b. Tutorial

Pada bagian menu, salah satu button berisi Tutorial. Agar User mengerti aturan dan beberapa hal tentang game, tutorial dibuat dalam bentuk video. Pada video, terdapat pengaturan pause dan play, juga slider yang berguna agar user dapat menghentikan dan juga melanjutkan video ketika sedang menonton tutorial yang dibuat. 
Vol. 2, No. 1, March 2020

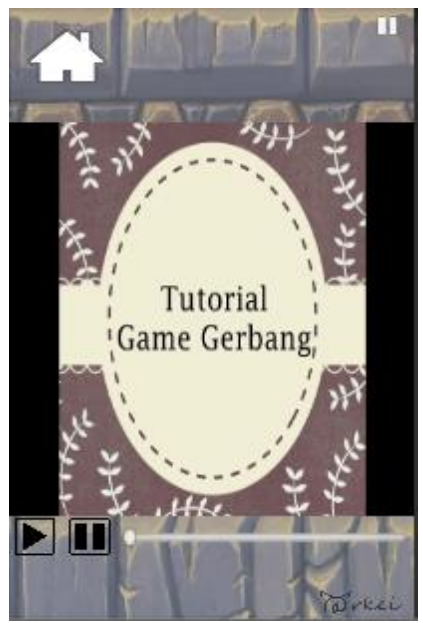

Gambar 3.3: Tutorial

c. Pilihan Karakter

Sebelum memulai permainan, user akan terlebih dahulu memilih avatar atau karakter yang ingin dimainkan.

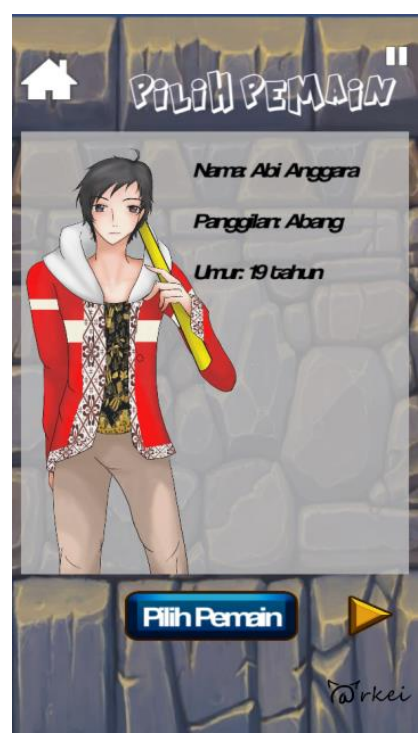

Gambar 3.4: Pilihan Karakter

Terdapat dua pilihan karakter, yaitu Abang dan Uti. Masing-masing karakter akan tampil sesuai dengan apa yang user pilih katika permainan berlangsung. Pilihan karakter ini diharapkan juga dapat menumbuhkan minat pemain/user. Kedua karakter yang tersedia merupakan karakter laki-laki dan karakter perempuan, sehingga pemain lebih merasa bebas memilih sesuai dengan selera mareka. 
Vol. 2, No. 1, March 2020

p-ISSN: 2656-5935 http://journal-isi.org/index.php/isi

e-ISSN: 2656-4882

d. Pilihan Negara

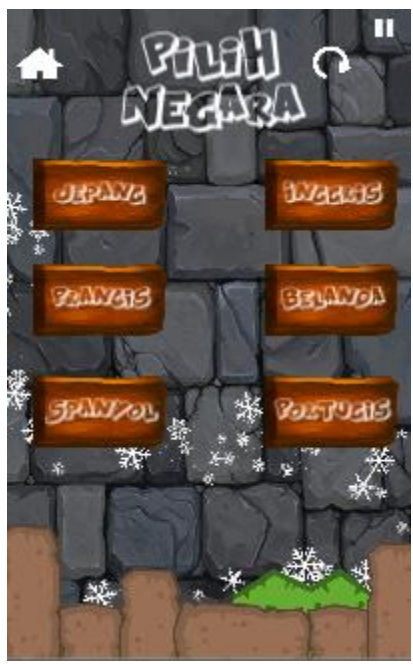

Gambar 3.5: Pilihan Negara

Setelah memilih karakter, user / pemain akan memilih negara mana yang ingin mereka lawan. Pilihan ini juga merupakan batasan soal-soal yang akan dijawab oleh pemain. Setiap pilihan yang dipilih, merupakan tema soal selama rentan waktu negara tersebut menjajah Indoneisa. Terdapat enam negara yang diambil, yaitu: Jepang, Inggris, Prancis, Belanda, Spanyol dan Portugis.

e. Permainan

Ketika pemain selesai memilih negara, maka akan muncul tampilan permainan. Di dalam game Gerbang, permainan ini merupakan game tanya-jawab yang merupakan kumpulan soal seputar sejarah penjajahan di Indonesia. Untuk mempermudah pemain dalam menjawab soal yang diberikan, game gerbang membuat tiga pilihan dimana pemain hanya tinggal memencet pilihan mana menurutnya benar.

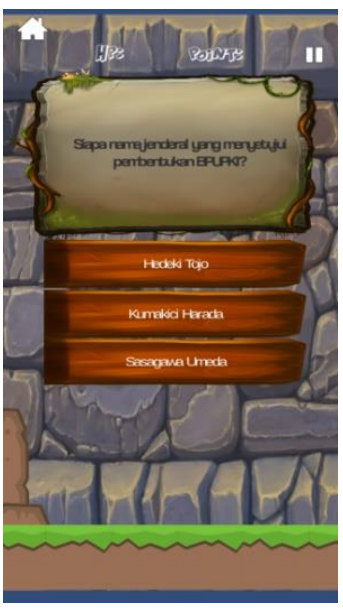

Gambar 3.6: Permainan 
Terdapat 50 pertanyaan yang berbeda di dalam game, masing-masing pertanyaan akan keluar secara acak sehingga user / pemain cenderung menemukan soal yang berbeda. f. Jawaban Benar dan Salah

Di dalam game Gerbang, agar permainan menjadi lebih menarik, akan ada aksi dan reaksi yang diberikan, itu sebabnya pemilihan karakter sebelum dimulainya game diperlukan. Apabila User menjawab dengan benar, maka gambar pemain akan menyerang penjajah dan penjajah akan terbaring di tanah.

Penjajah akan terus terbaring dan tidak bisa bangkit selama pemain menjawab dengan benar. Namun bila pemain menjawab salah, penjajah akan menyerang user/pemain dan pemain akan terus terbaring sampai akhirnya menjawab pertanyaan dengan benar.

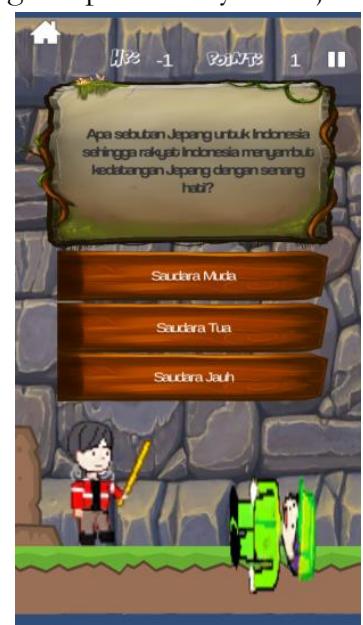

Gambar 3.7: Menjawab Benar

Di dalam game juga terdapat Poin dan HP(bit point). Poin dan HP ini untuk menentukan apakah user/pemain berhasil atau tidak bisa melawan penjajah. Apabila jumlah HP mencapai -3, atau pemain mendapatkan tiga pukulan karena salah menjawab pertanyaan sebanyak tiga kali, maka pemain akan kalah.

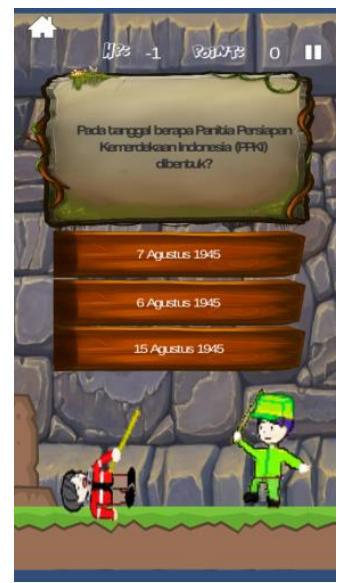

Gambar 3.8: Menjawab Salah 
Vol. 2, No. 1, March 2020

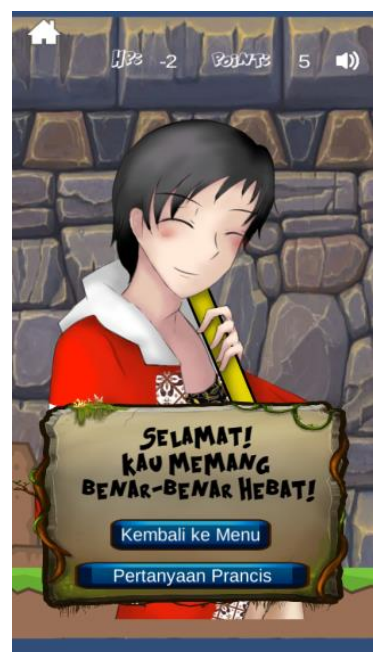

Gambar 3.9: Pemain Menang

Tetapi, bila pemain berhasil mencetak skor poin hingga 5 atau memukul musuh hingga lima kali dan nilai HP kurang dari -3 , maka pemain dikatakan menang melawan penjajah.

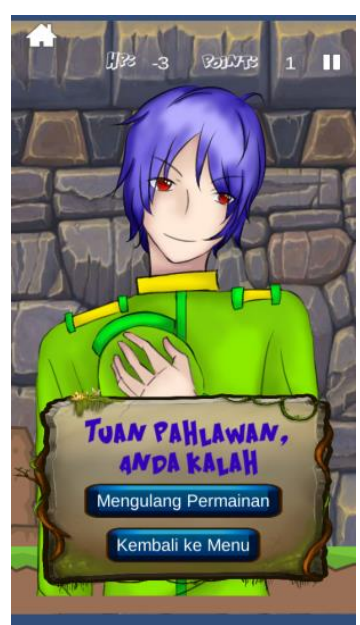

Gambar 3.10: Pemain Kalah

\subsubsection{Beta Testing}

Setelah game selesai, maka yang harus dilakukan adalah tahapan pengujian. Pada game Gerbang, pengujian menggunakan Balck Box Testing, dimana merupakan metode pengujian yang hanya melihat hasil akhri dan mengetes apakah tombol dan sistem pada game Gerbang dapat berjalan sesuai dengan fungsi yang diharapkan atau tidak. 


\section{KESIMPULAN}

Kesimpulan yang diperoleh setelah game Gerbang selesai dibuat adalah:

1. Penggunaan IMSDD (Interactive Multimedia System of Design and Development) cocok untuk digunakan sebagai metode pembangunan game atau beberapa aplikasi sejenis yang memerlukan perpaduan media interaktif.

2. Pada game Gerbang yang telah diselesaikan, soal-soal yang menjadi permainan di dalamnya secara tidak langsung dapat menjadi media pembelajaran.

3. Interface pada game Gerbang menggunakan bahasa Indonesia, baik pada bottom atau soal yang diberikan. Karena hal itu, game Gerbang mempermudah beberapa orang yang tidak mengerti bahasa inggris untuk memainkannya.

\section{DAFTAR PUSTAKA}

Amperiyanto, T. (2014). Tips Ampuh Android. Jakarta: PT Alex Media Komputindo.

Dastbaz, M. (2003). Interactive Multimedia System. New York: McGrawHill.

Leyton-Brown, k dan Shoham. (2008). Essentials of Games Theory. United States of America: Morgan \& Claypool.

Madya, S. (2006). Teoir dan Praktik Penelitian Tindakan Action Research. Bandung: Alfabeta.

Meier, R. (2009). Professional Android 4 Application Development. United States of America: Wiley Publishing,.Inc.

Moeliono, M. D. (1988). Kamus Besar Bahasa Indonesia. Jakarta: Balai Pustaka.

Roedawan, R. (2018). Unity Tutorial Game Engine Plus CD Revisi ke Dua. Bandung: Informatika.

Schell, J. (2008). The Art of Game Design A Book OfLenses. United States of America: Morgan Kaufmann Publishers.

Simarmata, J. (2010). Rekayasa Perangkat Lunak. Yogyakarta : Andi.

Sugiyono. (2002). Metode Penelitian Pendidikan Pendekatakn Kuantitaif, Kualitatif, dan R\&D. Bandung: Alfabeta.

Uyung, S. (2004). Management Perubahan. Yogyakarta: Pustaka Offset. 